(RESEARCH ARTICLE)

\title{
Cervical cancer - statistical analysis data for 2016 and 2017 in Republic of North Macedonia
}

\author{
Jihe Zhu 1, Blagica Arsovska 1,2 and Kristina Kozovska 1,3,* \\ ${ }^{1}$ Faculty of Medical Sciences, University Goce Delchev, Shtip, Republic of Macedonia. \\ ${ }^{2}$ Institute of Biology, Faculty of Natural Sciences and Mathematics, Skopje, Republic of Macedonia. \\ ${ }^{3}$ Medicine Faculty, St. Cyril and Methodius University of Skopje, Republic of Macedonia.
}

Publication history: Received on 11 August 2020; revised on 23 August 2020; accepted on 26 August 2020

Article DOI: https://doi.org/10.30574/wjarr.2020.7.2.0297

\begin{abstract}
The exceptional accessibility of the cervix (cervix uteri) and direct physical examination have allowed intensive research into the nature of the malignant lesions of the cervix. Studies have shown that many of these tumors have no explosive but gradual onset. Their pre-invasive antecedents may persist for two-way surfaces or in situ disease for several years, although this may change, at least in some patients. There is convincing evidence that the cytological screening programs are effective in reducing mortality from cervical cancer. Screening has not only reduced the incidence and mortality rate but has also found many women with pre-invasive neoplasia (which is the role of screening rather than diagnosing cancer). From the results of the Institute of Public Health of the Republic of Northern Macedonia for two years 2016 and 2017, it is concluded that the cervical cancer mortality rate in 2016 is significantly higher than in 2017, where the screening program is more developed and higher and there's more coverage of at-risk patient group (50+ years). In 2016, 87.4\% had normal results, while $12.6 \%$ had cellular abnormalities, compared to $2017-76.2 \%$ had normal results, while $23.8 \%$ had cellular abnormalities. The mortality rate in 2017 from cervical cancer is 30 which is lower than in 2016. This situation points to the necessity of increasing the coverage of women in the Program for screening and promoting the implementation of the Program by the Ministry of Health as soon as possible.
\end{abstract}

Keywords: Statistics; Cervix; Cancer; Neoplasia; Screening

\section{Introduction}

Cervical cancer is a malignant neoplasm of the cervix or cervical surface. Cervical cancer is the second most common type of cancer in women worldwide and is associated with sexually transmitted genital infections, namely human papillomavirus (HPV). Cervical cancer can be considered a "controlled" cancer. It is preceded by a recognizable lesion (cervical intraepithelial neoplasia, CIN) that may (but not always) progress to invasive cancer. Targeted education, screening, and intervention can reduce the burden of disease. CIN can be treated with simple and effective treatments, including cryotherapy, laser ablation, electrosurgical loop excision (LEEP), and cold knife cone biopsy, all of which have a high cure rate.

Risk factors for cervical cancer include numerous sexual partners, but increased data show that women may be at increased risk for their sexual partner, where her partner's sexual history is also extremely important. Persistent HPV infection increases the risk of progressive or persistent cervical dysplasia. Higher incidence of HPV infection and progression of intraepithelial neoplasia is seen in immunosuppressive patients, including those infected with HIV, as well as those undergoing organ transplantation, those with chronic renal failure, or a history of Hodgkin's lymphoma. Smoking is now also considered a high-risk factor for cervical cancer. Individuals may be genetically predisposed to cervical cancer, but the relative risks are small.

\footnotetext{
${ }^{*}$ Corresponding author: Kristina Kozovska

Faculty of Medical Sciences, University Goce Delchev, Shtip, Republic of Macedonia.
} 
For the diagnosis of cervical cancer is applied colposcopy, a colposcopic examination of the female genital tract does not take more than a few minutes, cytological screening, colposcopically targeted biopsies, ESS and pelvic examination. Therapy is indicated for women with CIN 2 or CIN 3. This also applies to those women with CIN 1. Treatment includes observation, local excision, electrocautery, cryosurgery, laser, cold coagulation, electrosurgical excision procedure (LEEP), conization, hysterectomy. No therapy is $100 \%$ effective, and the relationship between the patient's benefit and risk should be explained so that she is fully informed. For recurrent and advanced cervical cancer as therapy is applied - radical hysterectomy, radiation, chemotherapy. Symptoms of advanced cervical cancer may include: loss of appetite, weight loss, fatigue, pelvic pain, back pain, leg pain, unilateral swollen leg, heavy vaginal bleeding, leaking urine, or vaginal stools and bone fractures. [1-8].

\section{Material and methods}

Archival data has been used for statistics at the level of the whole country from the Institute of Public Health of the Republic of Northern Macedonia (RNM) in a period of 2 years - 2016 and 2017. Data were taken on the total number of patients and deceased by age, as well as the number of patients with abnormal PAP swabs. A consultation was made in order to be more informed about the disease with specialist doctors - gynecologists, statistics have been made on the number of deceased from cervical cancer in the Republic of Northern Macedonia in the period 2008-2017, emphasizing the importance of PAP screening and its application in RNM for the period 2012-2018.

\section{Results and discussion}

In the Republic of Northern Macedonia, a Program for Early Detection and Prevention of Cervical Cancer in Women has been implemented since 2007, through which a free Pap test was provided nationwide for all women aged 24-65. From 2009 to 2011 in the Republic of Macedonia was conducted pilot cervical cancer screening in 4 pilot municipalities (Prilep, Gostivar, Stip and Sveti Nikole) for all women aged 30-55 years. In 2012, organized cervical cancer screening was started in the Republic of Macedonia for all women aged 24-35. In 2012, the Government of the Republic of Macedonia adopted a Program for early detection of malignant diseases, which started on 01.04.2012. Statistics from the Institute of Public Health of the Republic of Northern Macedonia in the period 2016-2017 are presented separately.

Table 1 Cervical Cancer Screening Results in the Republic of Northern Macedonia for 2016

\begin{tabular}{|l|l|}
\hline Cancer type & $\mathbf{2 0 1 6} \mathbf{y}$. \\
\hline Squamous cell carcinoma suspected of invading & 3 \\
\hline Invasive squamous cell carcinoma & 2 \\
\hline Adenocarcinoma in situ & 0 \\
\hline Cervical adenocarcinoma & 1 \\
\hline Adenocarcinoma not otherwise specified NOS & 0 \\
\hline Another malignant neoplasm & 0 \\
\hline
\end{tabular}

Normal results were obtained in $87.4 \%$, while cellular abnormalities were detected in $12.6 \%$ of the cases. The screening revealed 6 cases of cancer, of which 3 squamous cell carcinoma suspected of invasion, 2 invasive squamous cell carcinoma, and 1 case of cervical adenocarcinoma. Of the total number of pathological lesions, the most common are CIN 1 (40.4\%), HPV (33\%) and ASCUS (15.3\%).

Table 2 Cervical Cancer Screening Results in the Republic of Northern Macedonia for 2017.

\begin{tabular}{|l|l|}
\hline Cancer type & $\mathbf{2 0 1 7} \mathbf{y}$. \\
\hline Squamous cell carcinoma suspected of invading & 16 \\
\hline Invasive squamous cell carcinoma & 8 \\
\hline Adenocarcinoma in situ & 4 \\
\hline Cervical adenocarcinoma & 0 \\
\hline Adenocarcinoma not otherwise specified NOS & 12 \\
\hline Another malignant neoplasm & 8 \\
\hline
\end{tabular}


Normal results were obtained in $76.2 \%$, while cellular abnormalities were detected in $23.8 \%$. The screening revealed 48 cases of cancer, of which 16 squamous cell carcinoma suspected of invasion, 8 invasive squamous cell carcinoma, 4 adenocarcinoma in situ, 2 adenocarcinoma not otherwise specified NOS and 18 other malignant neoplasms. Of the total number of pathological lesions, the most common are CIN 1 (44.4\%), HPV (38\%) and ASCUS (19.3\%).



Figure 1 Total abnormal cervical screening results in the Republic of Northern Macedonia for2016 and 2017

Table 3 Deceased from cervical cancer in 2016 by age; rate per 100,000 women 4.54 .

\begin{tabular}{|l|l|l|l|l|l|l|l|l|l|l|l|l|l|l|}
\hline & Total & $\mathbf{2 5 -}$ & $\mathbf{2 8 -}$ & $\mathbf{3 0 -}$ & $\mathbf{3 5 -}$ & $\mathbf{4 0 -}$ & $\mathbf{4 5 -}$ & $\mathbf{5 0 -}$ & $\mathbf{5 5 -}$ & $\mathbf{6 0 -}$ & $\mathbf{6 5 -}$ & $\mathbf{7 0 -}$ & $\mathbf{7 5 -}$ & $\mathbf{8 0 +}$ \\
& & $\mathbf{2 7}$ & $\mathbf{2 9}$ & $\mathbf{3 4}$ & $\mathbf{3 9}$ & $\mathbf{4 4}$ & $\mathbf{4 9}$ & $\mathbf{5 4}$ & $\mathbf{5 9}$ & $\mathbf{6 4}$ & $\mathbf{6 9}$ & $\mathbf{7 4}$ & $\mathbf{7 9}$ & \\
\hline C53 & 47 & & 1 & 3 & 3 & 3 & 2 & 7 & 6 & 2 & 6 & 3 & 4 & 7 \\
\hline
\end{tabular}

Table 4 Deceased from cervical cancer in 2017 by age; rate per 100,000 women: 2,89

\begin{tabular}{|l|l|l|l|l|l|l|l|l|l|l|l|l|l|l|}
\hline & Total & $\mathbf{2 5 -}$ & $\mathbf{2 8 -}$ & $\mathbf{3 0 -}$ & $\mathbf{3 5 -}$ & $\mathbf{4 0 -}$ & $\mathbf{4 5 -}$ & $\mathbf{5 0 -}$ & $\mathbf{5 5 -}$ & $\mathbf{6 0 -}$ & $\mathbf{6 5 -}$ & $\mathbf{7 0 -}$ & $\mathbf{7 5 -}$ & $\mathbf{8 0 +}$ \\
& & $\mathbf{2 7}$ & $\mathbf{2 9}$ & $\mathbf{3 4}$ & $\mathbf{3 9}$ & $\mathbf{4 4}$ & $\mathbf{4 9}$ & $\mathbf{5 4}$ & $\mathbf{5 9}$ & $\mathbf{6 4}$ & $\mathbf{6 9}$ & $\mathbf{7 4}$ & $\mathbf{7 9}$ & \\
\hline $\mathrm{C53}$ & 30 & 1 & - & 3 & 1 & 2 & 2 & 5 & 4 & - & 4 & 2 & 2 & 4 \\
\hline
\end{tabular}

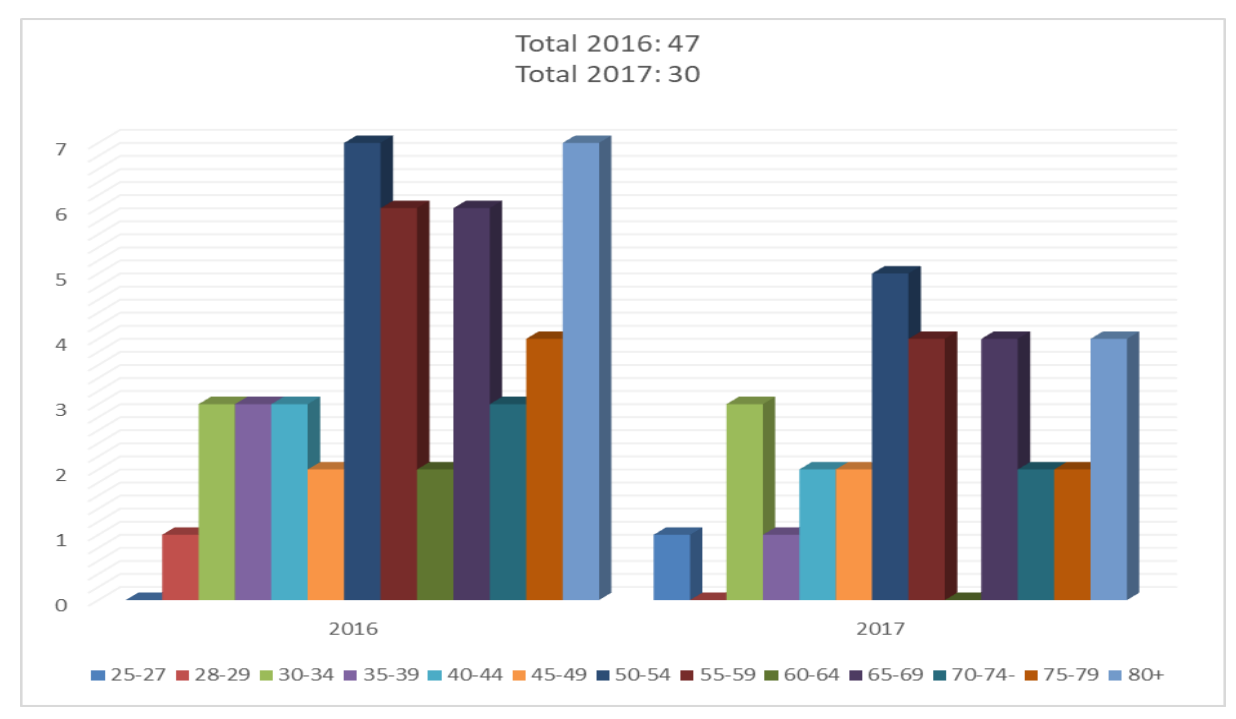

Figure 2 Total cervical cancer deaths in 2016 and 2017 by age 
World Journal of Advanced Research and Reviews, 2020, 07(02), 200-205

Table 5 Total number of deaths from cervical cancer in the period 2008-2017 in the Republic of Northern Macedonia

\begin{tabular}{|l|l|l|}
\hline Year & Total number of deaths & Rate of $\mathbf{1 0 0 0 0}$ \\
\hline 2008 & 43 & 4,21 \\
\hline 2009 & 35 & 3,42 \\
\hline 2010 & 31 & 3,02 \\
\hline 2011 & 15 & 1,46 \\
\hline 2012 & 39 & 3,79 \\
\hline 2013 & 36 & 3,49 \\
\hline 2014 & 42 & 4,07 \\
\hline 2015 & 39 & 3,77 \\
\hline 2016 & 47 & 4,54 \\
\hline 2017 & 30 & 2,89 \\
\hline
\end{tabular}

Starting from 2012 until today, there is a positive trend in the number of women covered by screening.

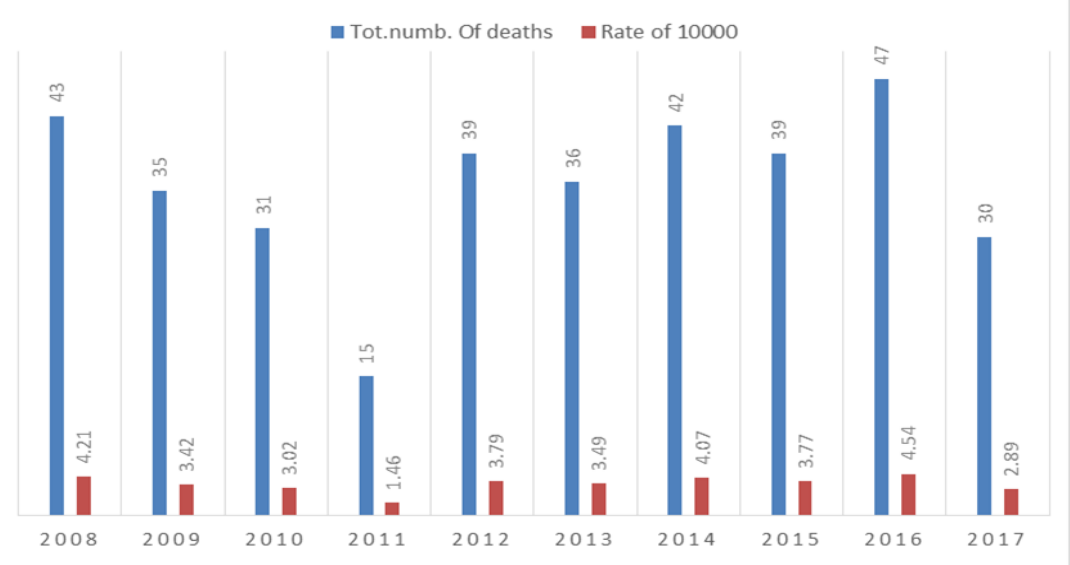

Figure 3 Total number of deaths from cervical cancer in the period 2008-2017 in the Republic of Northern Macedonia Table 6 Number of PAP tests performed through organized screening in RSM for the period 2012-2018.

\begin{tabular}{|l|l|}
\hline Year & Number of PAP tests \\
\hline 2012 & 17595 \\
\hline 2013 & 20612 \\
\hline 2014 & 26270 \\
\hline 2015 & 29887 \\
\hline 2016 & 29118 \\
\hline 2017 & 27138 \\
\hline Јануари- септември 2018 & 31630 \\
\hline
\end{tabular}




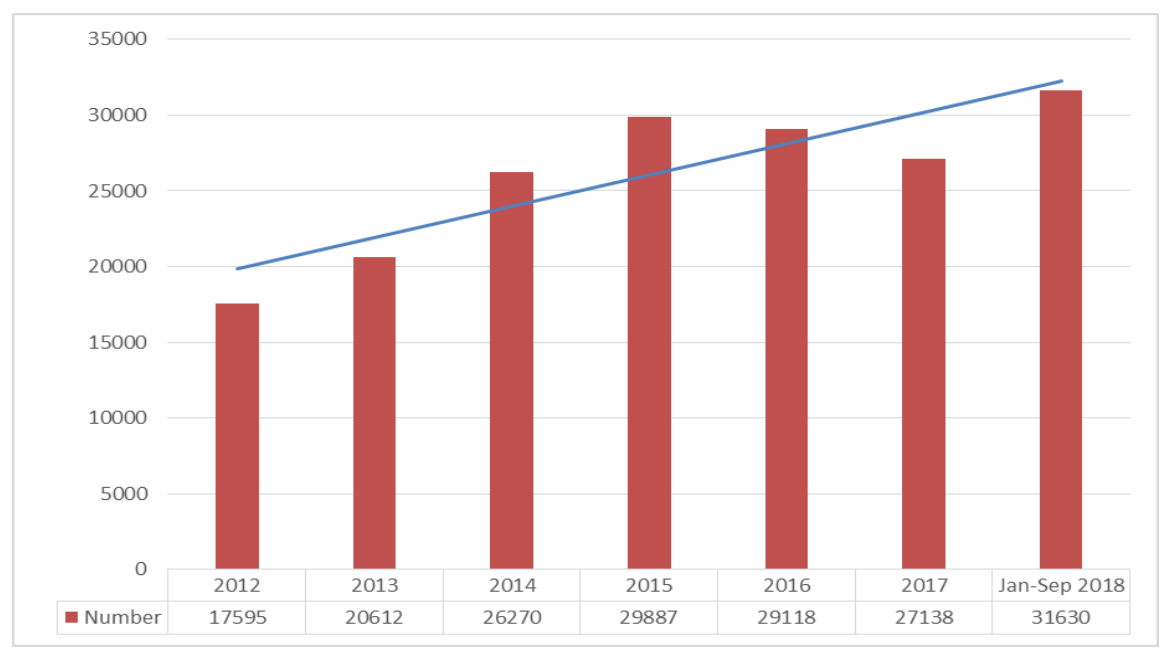

Figure 4 Number of PAP tests performed through organized screening in RNM for the period 2012-2018

According to the data taken from the Institute of Public Health of the Republic of Northern Macedonia, it can be concluded that over the years mortality from cervical cancer is declining. According to the data and the comparison between the two years 2016 and 2017, the importance of screening for early detection of abnormalities in women can be seen. In $2016,87.4 \%$ received normal results, while $12.6 \%$ had cellular abnormalities, compared to $2017-76.2 \%$ received normal results, while 23.8\% had cellular abnormalities. Screening in 2016 revealed 6 cases of cancer of which 3 squamous cell carcinoma suspected of invasion, 2 invasive squamous cell carcinoma, and 1 case of cervical adenocarcinoma but there are a large number of women in the risk group (50+ years and other risk factors) as well as insufficiently informed women who did not attend the examination and who did not have a PAP test, therefore the mortality in the same year is 47 , compared to 2017 when normal results were detected in $76.2 \%$, while cellular abnormalities were detected in $23.8 \%$, of which 48 cases of cancer were detected by screening, of which 16 squamous cell carcinoma suspected of invasion, 8 invasive squamous cell carcinoma, 4 adenocarcinoma in situ, 2 adenocarcinoma not otherwise specified NOS and 18 other malignant neoplasms. The mortality rate in 2017 from cervical cancer is 30 and is lower than in 2016, so that within the organized screening in 2017, 27,138 women aged 46 to 60 were preventively examined, as well as the age groups that did not have a Pap smear in 2016. This is due to the greater awareness of women about the importance of screening as prevention of their health, which is confirmed by the number of screening examinations performed from January to September 2018, which is the highest so far and is 31,630.

\section{Conclusion}

With proper prevention, early detection of precancerous lesions can control the disease and significantly reduce mortality. The Ministry of Health of the Republic of Northern Macedonia follows the trends of the developed countries in the field of reproductive health, respecting the three principles for protection of women's health through:

- Introduction of HPV vaccination in the regular immunization calendar

- Organized screening - regular gynecological examinations with free PAP - test

- Early detection and treatment of cervical cancer

By increasing the level of knowledge and informing women (target group) about the disease and the need to perform preventive examinations and to motivate them to perform the examination, there is a timely detection and treatment of the disease and thus reduce mortality.

\section{Compliance with ethical standards}

\section{Disclosure of conflict of interest}

The authors declare that there is no conflict of interest. 


\section{Statement of informed consent}

Informed consent was obtained from the participant included in the study.

\section{References}

[1] FD Disana, WT Krisman (2011); Clinical gynecological oncology; Tabernakul, Skopje

[2] CRB Beckmann, FW Ling (2009); Obstetrics and Gynecology - Sixth Edition; Wolters Kluwer

[3] JS Berek (2012); Berek \& Novak's Gynecology -Fifteenth edition; Wolters Kluwer

[4] S Oncheva (2018); Results from the screening for prevention and early detection of cervical cancer in the Republic of Northern Macedonia - Institute of Public Health of RNM [www.iph.mk]

[5] H Gelband, P Jha, R Sankaranarayanan et al (2015); Cancer: Disease Control Priorities, Third Edition (Volume 3); The International Bank for Reconstruction and Development / The World Bank

[6] Acibadem Sistina (2020); Cervical cancer [www.cancertreatment.mk]

[7] World Health Organization (2020); Cervical Cancer [www.who.int]

[8] F Bray et al. (2018); Global cancer statistics 2018: GLOBOCAN estimates of incidence and mortality worldwide for 36 cancers in 185 countries; A Cancer Journal for Clinicians; Volume 68, Issue 6 